\section{Lewis base mediated dismutation of trichlorosilane $\dagger \ddagger$}

\author{
Amit Pratap Singh, ${ }^{a}$ Rajendra S. Ghadwal, ${ }^{a}$ Herbert W. Roesky, ${ }^{* a}$ Julian J. Holstein, ${ }^{a}$ \\ Birger Dittrich, ${ }^{* a}$ Jean-Philippe Demers, ${ }^{b}$ Veniamin Chevelkov ${ }^{b}$ and Adam Lange ${ }^{b}$
}

Received 26th April 2012, Accepted 8th June 2012

DOI: $10.1039 / \mathrm{c} 2 \mathrm{cc} 33835 \mathrm{a}$

An abnormal N-heterocyclic carbene (aNHC) has been used as a Lewis base to initiate dismutation of trichlorosilane. This report presents the reactivity differences of a normal $\mathrm{N}$-heterocyclic carbene (NHC) versus aNHC with heavier group 14 elements. Three novel compounds $(\mathrm{NHC})_{2} \cdot \mathrm{SiCl}_{2} \mathrm{H}_{2}(2)$, aNHC$\cdot \mathrm{SiCl}_{2} \mathrm{H}_{2}(3)$, and aNHC. $\mathrm{GeCl}_{2}(4)$ have been synthesized and characterized by single crystal X-ray analysis, solid-state NMR and DFT calculations.

Trichlorosilane $\left(\mathrm{HSiCl}_{3}\right)$ is the most important precursor for the synthesis of numerous organosilicon derivatives and plays a significant role in the process of producing ultrapure silicon (Siemens process). ${ }^{1}$ Moreover, it is well known that the highly reactive trichlorosilane tends to dismutate in the presence of a base or at higher temperatures. These dismutation reactions often afford Lewis acid-base adducts as intermediates leading to the formation of silicon halides and silane $\left(\mathrm{SiH}_{4}\right)^{2}$ In the $1960 \mathrm{~s}$, Wannagat et al. ${ }^{3}$ reported on the first $1: 2$ adduct of trichlorosilane and pyridine (py) which undergoes the $\mathrm{H}$ versus $\mathrm{Cl}$ redistribution of $\mathrm{HSiCl}_{3}(\mathrm{py})_{2}$ in the presence of polar solvents to form the pyridine adducts of $\mathrm{H}_{2} \mathrm{SiCl}_{2}$ and $\mathrm{SiCl}_{4}$. In 1996, Fleischer et al. ${ }^{4}$ described the dismutation of bis(dichlorosilyl)amine in the presence of substituted pyridines (Rpy) to yield $\mathrm{H}_{3} \mathrm{SiCl}, \mathrm{H}_{2} \mathrm{SiCl}_{2}$, and $\mathrm{HSiCl}_{3}$ adducts. However, Boudjouk et al. ${ }^{5}$ reported the first structurally characterized dichlorosilane [(teeda) $\cdot \mathrm{SiCl}_{2} \mathrm{H}_{2}$ ] adduct, obtained from the dismutation of $\mathrm{HSiCl}_{3}$ in the presence of $N, N, N^{\prime}, N^{\prime}$-tetraethyl-1,2ethanediamine (teeda). In a more recent report, Kroke et al. ${ }^{6}$ described the dismutation reaction of $\mathrm{HSiCl}_{3}(\mathrm{Rpy})_{2}$, which exhibits various substitution patterns $\left(\mathrm{R}=\mathrm{H}, 3-\mathrm{Br}, 4-\mathrm{CHCH}_{2}, 4-\mathrm{CH}_{3}\right.$, 4- $\mathrm{C}\left(\mathrm{CH}_{3}\right)_{3}, 4-\mathrm{N}\left(\mathrm{CH}_{3}\right)_{2}$, and $\left.4-\mathrm{CH}_{2} \mathrm{CH}_{3}\right)$ on the pyridine molecule (py). In all these investigations, the dismutation of trichlorosilane results in octahedral adducts of dichlorosilane. In contrast, we have selectively synthesized a five coordinated aNHC. $\mathrm{SiCl}_{2} \mathrm{H}_{2}(3)$ adduct of dichlorosilane under mild conditions during the dismutation of trichlorosilane in the presence of aNHC as a Lewis base.

\footnotetext{
${ }^{a}$ Institut für Anorganische Chemie, Georg-August-Universität, Tammannstrasse 4, 37077 Göttingen, Germany.

E-mail:hroesky@gwdg.de,bdittri@gwdg.de,

rghadwal@uni-goettingen.de

${ }^{b}$ Max-Planck-Institut für Biophysikalische Chemie, Am Faßberg 11, D-37077 Göttingen, Germany

$\dagger$ This paper is dedicated to Professor Heribert Offermanns on the occasion of his 75 th birthday.

$\ddagger$ Electronic supplementary information (ESI) available: Experimental details, solid-state NMR and theoretical details. CCDC 883982 (2), 876665 (3) and 876666 (4). For ESI and crystallographic data in CIF or other electronic format see DOI: $10.1039 / \mathrm{c} 2 \mathrm{cc} 33835 \mathrm{a}$
}

We are not aware of any five coordinated dichlorosilane adduct during the dismutation of trichlorosilane.

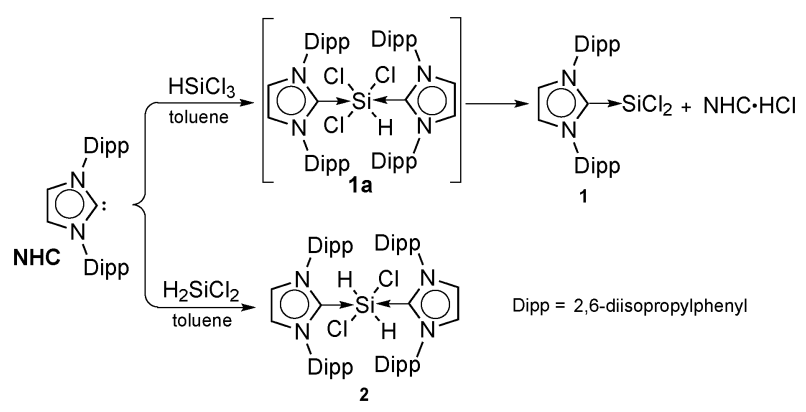

Scheme 1 Synthesis of compounds 1 and 2.

Recently, we reported a room temperature stable Lewis base stabilized dichlorosilylene $\mathrm{NHC} \cdot \mathrm{SiCl}_{2}$ (1) by reductive elimination of $\mathrm{HCl}$ from $\mathrm{HSiCl}_{3}$ in the presence of $\mathrm{NHC}$ (Scheme 1). ${ }^{7}$ NHCs have been extensively used as versatile ligands in main group as well as in transition metal chemistry. ${ }^{8,9}$ Typically NHCs form metal complexes through the carbene center adjacent to two nitrogen atoms. In 2009, Bertrand et al. ${ }^{10}$ reported an abnormal N-heterocyclic carbene (aNHC) where the carbene center has only one adjacent nitrogen atom. Experimental data suggest that the aNHC is a strong nucleophile as well as an electrophile and may be a better substitute for NHCs. Therefore we became interested in exploring the chemistry of aNHC with heavier group 14 elements such as silicon and germanium.

The reaction of aNHC with $\mathrm{HSiCl}_{3}$ gives the $1: 1 \mathrm{aNHC}$. $\mathrm{SiCl}_{2} \mathrm{H}_{2}$ (3) adduct under elimination of $\mathrm{SiCl}_{4}$. A similar reaction with $\mathrm{NHC}$ produces dichlorosilylene 1. We assume that in the case of NHC, the six coordinated intermediate 1a is formed (Scheme 1) which undergoes reductive elimination of $\mathrm{HCl}$ to produce compound $\mathbf{1}$. However, in the case of aNHC,

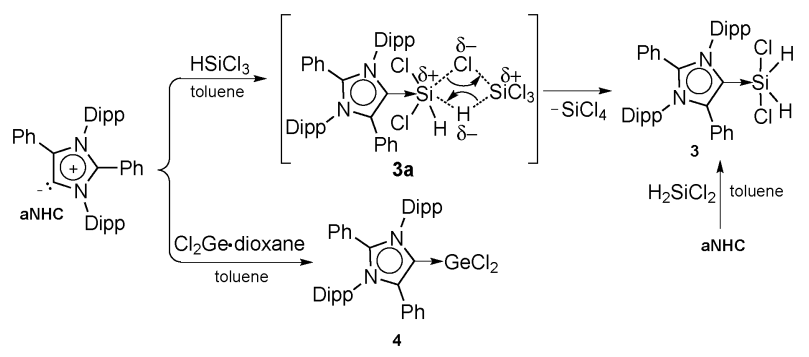

Scheme 2 Synthesis of compounds 3 and 4 . 
the presence of bulkier substituents resists the formation of a six coordinated intermediate with another molecule of aNHC. Moreover, the strong nucleophilic nature of aNHC favours the formation of an intermediate $\mathbf{3 a}$ involving two molecules of $\mathrm{HSiCl}_{3}$ (Scheme 2), resulting in the formation of $\mathbf{3}$ under elimination of $\mathrm{SiCl}_{4}$. The formation of compound 2 by the reaction of $\mathrm{H}_{2} \mathrm{SiCl}_{2}$ with $\mathrm{NHC}$ (Scheme 1) strongly supports the formation of a six coordinated intermediate during the reaction of $\mathrm{NHC}$ with $\mathrm{HSiCl}_{3}$. Furthermore, we obtained the five coordinated adduct 3 from the reaction of aNHC with $\mathrm{H}_{2} \mathrm{SiCl}_{2}$. For a comparative study aNHC. $\mathrm{GeCl}_{2}$ (4) was synthesized by the addition of $\mathrm{Cl}_{2} \mathrm{Ge}$-dioxane to the toluene solution of aNHC in a $1: 1$ molar ratio. All compounds have been characterized by their ${ }^{1} \mathrm{H}$ and ${ }^{13} \mathrm{C}$ NMR spectra and show resonances for their respective ligands. Additionally, the ${ }^{1} \mathrm{H}$ NMR spectra of compounds $\mathbf{2}$ and $\mathbf{3}$ show a slightly broad resonance for the two $\mathrm{Si}-\mathrm{H}$ protons at 5.58 and $6.14 \mathrm{ppm}$, respectively. To investigate the electronic environments around the silicon center for compounds $\mathbf{2}$ and $\mathbf{3}$ solid- and solution-state ${ }^{29} \mathrm{Si}$ NMR spectra were recorded. The solutionstate ${ }^{29} \mathrm{Si}$ NMR spectra show the resonances at $-225.2^{11}$ and $-118.2 \mathrm{ppm}$ for $\mathbf{2}$ and $\mathbf{3}$, respectively. The ${ }^{29} \mathrm{Si}$ solid-state NMR spectrum of $\mathbf{2}$ shows a resonance with an isotropic chemical shift of -225.2 ppm (Fig. 1 and Fig. S1, ESI $\ddagger$ ). Two ${ }^{29} \mathrm{Si}$ resonances are found for 3 , at $-118.0 \mathrm{ppm}$ and $-120.4 \mathrm{ppm}$, which could be due to polymorphism in the sample. The chemical shift anisotropy (CSA), determined from the intensity of the magic angle spinning (MAS) sideband pattern is $+24 \mathrm{ppm}$ for $\mathbf{2}$ and $+112 \mathrm{ppm}$ for $\mathbf{3}$. The very negative chemical shift of $\mathbf{2}$ arises as both NHC ligands contribute to the electron rich environment at the $\mathrm{Si}$ nucleus. Furthermore, in contrast to $\mathbf{2}$, which has a small CSA due to the molecular symmetry, the single aNHC ligand in $\mathbf{3}$ generates a large anisotropy of the electronic distribution at the $\mathrm{Si}$ nucleus (see ESI $\ddagger$, Table S1). Crosspolarization build-up curves for $\mathbf{2}$ and $\mathbf{3}$ reach their maximum intensity within $200 \mu \mathrm{s}$, confirming the presence of a directly bonded proton on $\mathrm{Si}$ atoms (see ESIł̣, Fig. S2). The elimination of $\mathrm{SiCl}_{4}$ during the dismutation reaction of trichlorosilane was confirmed by recording the ${ }^{29} \mathrm{Si}$ NMR spectrum of the reaction

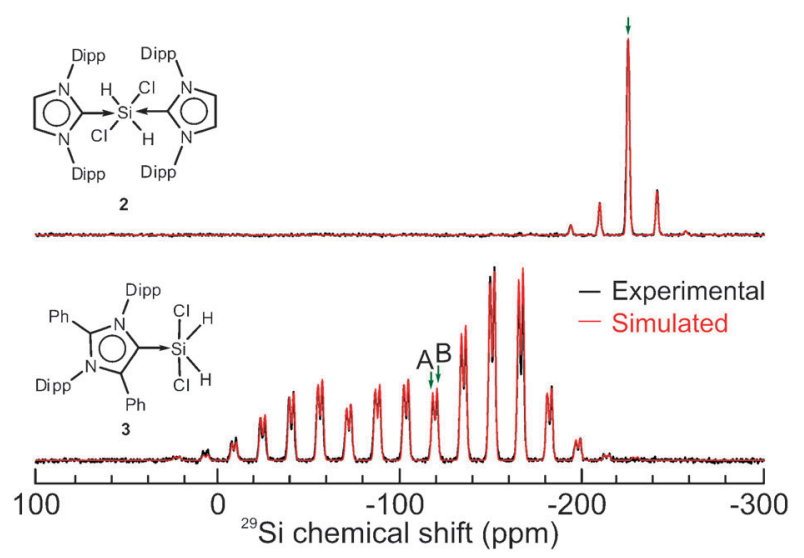

Fig. $1{ }^{29} \mathrm{Si}$ solid-state NMR cross-polarization spectra of $\mathbf{2}$ (top) and 3 (bottom) recorded at $1250 \mathrm{~Hz}$ MAS. Isotropic peaks are indicated by arrows and back-calculated spectra are displayed in red. The high number of spinning sidebands for 3 illustrates the large anisotropy of the electronic environment at the silicon nucleus.

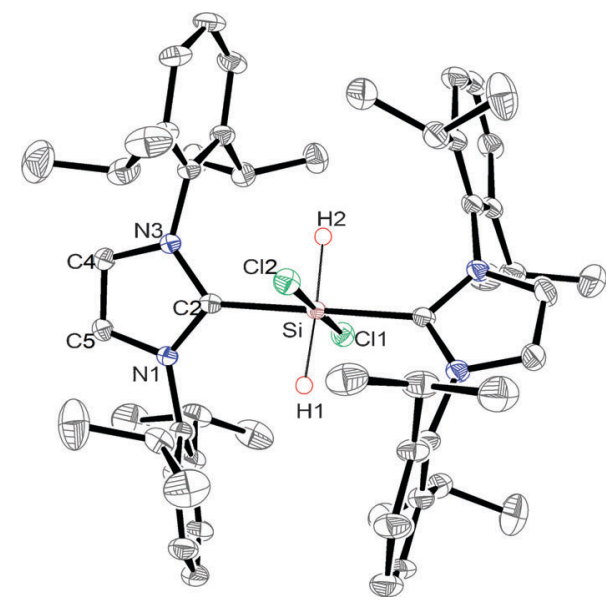

Fig. 2 ORTEP-representation of the molecular structure of $(\mathrm{NHC})_{2}$. $\mathrm{SiCl}_{2} \mathrm{H}_{2}$ (2). ADPs are depicted at the $50 \%$ probability level. All C-H hydrogen atoms are omitted for clarity. Selected bond lengths $(\AA)$ and angles $\left({ }^{\circ}\right)$ : $\mathrm{Si}-\mathrm{C}(2)$ 2.0494(15), $\mathrm{Si}-\mathrm{Cl}(1)$ 2.2871(5), $\mathrm{Si}-\mathrm{Cl}(2)$ 2.2850(5), C(2)-Si-Cl(1) 89.64(4), C(2)-Si-Cl(2) 90.23(4), Cl(1)-Si-Cl(2) 179.25(2).

mixture which shows an additional resonance at $-18.0 \mathrm{ppm}$ corresponding to $\mathrm{SiCl}_{4}{ }^{12}$

In order to establish unambiguously the structural features of compounds $\mathbf{2 - 4}$, single crystal X-ray structural analyses were carried out. The molecular structure of $\mathbf{2}$ reveals that two NHCs are coordinated to the $\mathrm{H}_{2} \mathrm{SiCl}_{2}$ molecule to afford a six coordinated $(\mathrm{NHC})_{2} \cdot \mathrm{SiCl}_{2} \mathrm{H}_{2}$ (2) adduct with an octahedral geometrical environment around the silicon center (Fig. 2). The NHC, hydrogen and chlorine which are coordinated to the silicon center have the same partner in the trans position. Both NHCs make an angle of $179.18(5)^{\circ}$ with a $\mathrm{C} 2-\mathrm{Si}$ bond length of 2.0494(15) $\AA$. The molecular structures of compounds 3 and $\mathbf{4}$ show that aNHC is coordinated to the $\mathrm{Si} \mathrm{(3)}$ and $\mathrm{Ge}(4)$ through the carbene center C5. The structure of 3 reveals that aNHC forms a five coordinated adduct with the $\mathrm{H}_{2} \mathrm{SiCl}_{2}$ resulting in a trigonal bipyramidal geometry around the silicon (Fig. 3). The carbon C5 and two hydrogen atoms

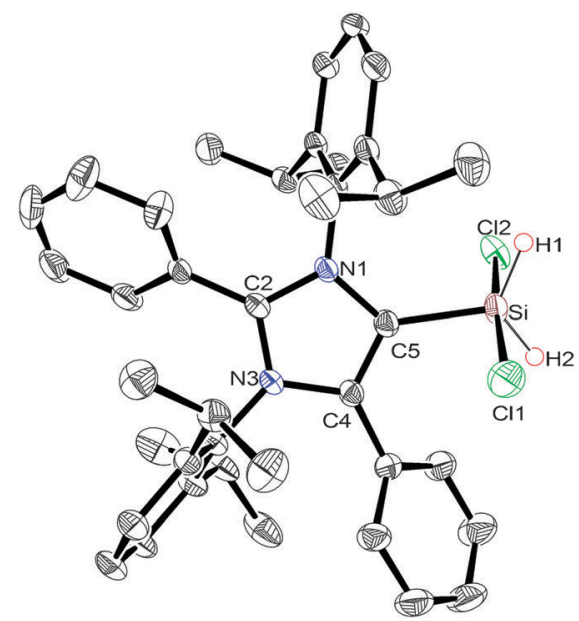

Fig. 3 ORTEP-representation of the molecular structure of aNHC $\mathrm{SiCl}_{2} \mathrm{H}_{2}(3)$. ADPs are depicted at the $50 \%$ probability level. Hydrogen atoms are omitted for clarity. Selected bond lengths $(\AA)$ and angles $\left({ }^{\circ}\right)$ : $\mathrm{Si}-\mathrm{C}(5)$ 1.908(2), Si-Cl(1) 2.2977(14), Si-Cl(2) 2.2992(11), C(5)-Si-Cl(1) 91.42(8), C(5)-Si-Cl(2) 91.98(8), Cl(1)-Si-Cl(5) 174.08(5). 


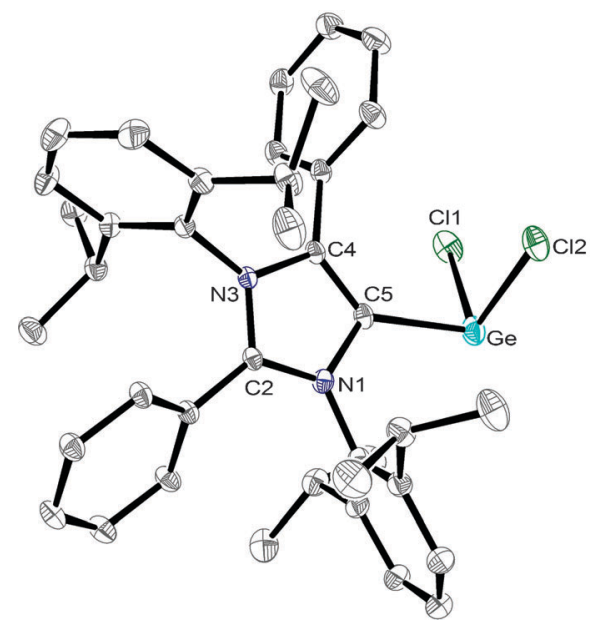

Fig. 4 ORTEP-representation of the molecular structure of aNHC. $\mathrm{GeCl}_{2}(4)$. ADPs are depicted at the $50 \%$ probability level. Hydrogen atoms are omitted for clarity. Selected bond lengths $(\AA)$ and angles $\left(^{\circ}\right)$ : $\mathrm{Ge}-\mathrm{C}(5)$ 2.071(2), Ge-Cl(1) 2.2856(7), Ge-Cl(2) 2.3157(6), C(5)-Ge-Cl(1) 92.91(6), C(5)- Ge-Cl(2) 93.33(6), Cl(1)-Si-Cl(2) 98.19(2).

( $\mathrm{H} 1$ and $\mathrm{H} 2$ ) are found in the trigonal plane, while the chlorine atoms ( $\mathrm{Cl} 1$ and $\mathrm{Cl} 2)$ occupy the axial positions. The average $\mathrm{Si}-\mathrm{Cl}$ bond lengths for compounds $\mathbf{2}$ and $\mathbf{3}$ are 2.286 and $2.298 \AA$, respectively. The chlorine atoms $\mathrm{Cl} 1$ and $\mathrm{Cl} 2$ form angles of $179.25(2)^{\circ}(2)$ and $174.08(5)^{\circ}(3)$ with silicon. In both 2 and 3 hydrogen atoms $(\mathrm{H} 1$ and $\mathrm{H} 2)$ coordinated to the silicon were located in the difference Fourier map (see ESI $\ddagger$, Fig. S3c and S4c) and were freely refined. The experimental Si-H lengths (1.477(19) and 1.461(18) $\AA$ ) in 2 are in good agreement with the theoretically predicted value $(1.478 \AA$ ). However, due to disorder or large amplitude vibrations, the experimentally determined $\mathrm{Si}-\mathrm{H}$ bond lengths (1.32(3) and $1.14(3) \AA)$ in 3 are different from the theoretically calculated value $(1.470 \AA)$. The molecular structure of 4 reveals that a distorted trigonal pyramidal geometry has been adopted by the coordinated germanium with the lone pair of electrons at the apex (Fig. 4 and Fig. S5, ESI $\ddagger$ ). Two chlorine atoms Cl1 and $\mathrm{Cl} 2$ are attached to the germanium with an average $\mathrm{Ge}-\mathrm{Cl}$ bond length of $2.301 \AA$, which is longer than that found in the analogous compound $\mathrm{NHC} \cdot \mathrm{GeCl}_{2}(2.277 \AA) .{ }^{13}$ Both chlorine atoms $\mathrm{Cl} 1$ and $\mathrm{Cl} 2$ are nearly perpendicular $\left(93.12^{\circ}\right)$ to the $\mathrm{Ge}-\mathrm{C} 5$ bond. The bond angle between the two chlorine atoms $\mathrm{Cl1}-\mathrm{Ge}-\mathrm{Cl} 2\left(98.19^{\circ}\right)$ is a little larger than that for the reported $\mathrm{Cl}-\mathrm{Ge}-\mathrm{Cl} 2\left(95.13^{\circ}\right)$ of $\mathrm{NHC} \cdot \mathrm{GeCl}_{2}$. The aNHC coordinated compounds have shorter $\mathrm{M}-\mathrm{C}_{\text {carbene }}$ bond lengths (1.908(2) $\AA$ (3) and 2.071(2) $\AA$ (4)) in comparison with that of NHC coordinated 2 and the reported $\mathrm{NHC} \cdot \mathrm{GeCl}_{2}(2.112(2) \AA) .{ }^{13}$ This is due to the strong nucleophilic nature of aNHC, resulting in a stronger $\mathrm{M}-\mathrm{C}$ bond. The DFT geometry-optimization results confirm that the calculated deformation densities show the expected electron density accumulations in the bonding regions (for more details see ESI

In summary, we have studied the reactivity differences of aNHC versus $\mathrm{NHC}$ towards $\mathrm{HSiCl}_{3}$ and $\mathrm{H}_{2} \mathrm{SiCl}_{2}$. A dismutation reaction of $\mathrm{HSiCl}_{3}$ occurred in the presence of aNHC resulting in a five coordinated aNHC. $\mathrm{SiCl}_{2} \mathrm{H}_{2}$ (3) adduct under elimination of $\mathrm{SiCl}_{4}$. However, a similar reaction of
$\mathrm{NHC}$ with $\mathrm{HSiCl}_{3}$ produces dichlorosilylene by reductive elimination of $\mathrm{HCl}$. In addition, a six coordinated $\mathbf{2}$ and a five coordinated $\mathbf{3}$ adduct was obtained by the reaction of $\mathrm{NHC}$ and of aNHC with $\mathrm{H}_{2} \mathrm{SiCl}_{2}$, respectively. This shows that aNHC is more nucleophilic as well as electrophilic in comparison to the NHC. Furthermore, dichlorogermylene aNHC. $\mathrm{GeCl}_{2}$ (4) was synthesized by the treatment of $\mathrm{Cl}_{2} \mathrm{Ge}$-dioxane with aNHC in a $1: 1$ molar ratio. The molecular structures of 2-4 were determined by single crystal $\mathrm{X}$-ray analysis and supported by DFT geometry-optimizations. Compounds 2-4 might prove to be promising candidates for the synthesis of other potentially important compounds with lowvalent silicon and germanium. Such type of investigations will be reported in due course from our laboratory.

Support from the Deutsche Forschungsgemeinschaft (DFG RO 224/60-1) (H.W.R.), Emmy Noether Fellowship (A.L. and B.D.) and the postgraduate scholarship from NSERC of Canada (J.-P.D.) are gratefully acknowledged.

\section{Notes and references}

1 (a) R. J. P. Corriu, Pure Appl. Chem., 1988, 60, 99-106; (b) R. J. P. Corriu, J. Organomet. Chem., 1990, 400, 81-106; (c) C. Chuit, R. J. P. Corriu, C. Reye and J. C. Young, Chem. Rev., 1993, 93, 1371-1448; (d) V. M. Vorotyntsev, G. M. Mochalov and O. V. Nipruk, Russ. J. Gen. Chem., 2001, 74, 621-625; (e) O. S. Fishman, Adv. Mater. Processes, 2008, 166, 39-40; $(f)$ G. W. Fester, J. Eckstein, D. Gerlach, J. Wagler, E. Brendler and E. Kroke, Inorg. Chem., 2010, 49, 2667-2673.

2 G. W. Fester, J. Wagler, E. Brendler and E. Kroke, Eur. J. Inorg. Chem., 2008, 5020-5023.

3 (a) U. Wannagat, K. Hensen and P. Petesch, Monatsh. Chem., 1967, 98, 1407-1414; (b) U. Wannagat, K. Hensen, P. Petesch and F. Vielberg, Monatsh. Chem., 1967, 98, 1415-1422.

4 (a) H. Fleischer, K. Hensen and T. Stumpf, Chem. Ber., 1996, 129, 765-771; (b) K. Hensen, T. Stumpf, M. Bolte, C. Näther and H. Fleischer, J. Am. Chem. Soc., 1998, 120, 10402-10408.

5 P. Boudjouk, S. D. Kloos, B.-K. Kim, M. Page and D. Thweatt, J. Chem. Soc., Dalton Trans., 1998, 877-879.

6 G. W. Fester, J. Wagler, E. Brendler, U. Böhme, D. Gerlach and E. Kroke, J. Am. Chem. Soc., 2009, 131, 6855-6864.

7 R. S. Ghadwal, H. W. Roesky, S. Merkel, J. Henn and D. Stalke, Angew. Chem., 2009, 121, 5793-5796 (Angew. Chem., Int. Ed., 2009, 48, 5683-5686).

8 (a) D. Bourissou, O. Guerret, F. P. Gabbaï and G. Bertrand, Chem. Rev., 2000, 100, 39-91; (b) S. T. Liddle, I. S. Edworthy and P. L. Arnold, Chem. Soc. Rev., 2007, 36, 1732-1744; (c) O. Kühl, Chem. Soc. Rev., 2007, 36, 592-607; (d) V. Dragutan, I. Dragutan, L. Delaude and A. Demonceau, Coord. Chem. Rev., 2007, 251, 765-794; (e) P. L. Arnold and S. Pearson, Coord. Chem. Rev., 2007, 251, 596-609; $(f)$ S. Díez-González and S. P. Nolan, Coord. Chem. Rev., 2007, 251, 874-883; (g) H. Jacobsen, A. Correa, A. Poater, C. Costabile and L. Cavallo, Coord. Chem. Rev., 2009, 253, 687-703; (h) P. de Frémont, N. Marion and S. P. Nolan, Coord. Chem. Rev., 2009, 253, 862-892.

9 (a) N-Heterocyclic Carbenes in Transition Metal Catalysis, Topics in Organometallic Chemistry, ed. F. Glorius, SpringerVerlag, Berlin, 2007, vol. 21; (b) F. E. Hahn and M. C. Jahnke, Angew. Chem., 2008, 120, 3166-3216 (Angew. Chem., Int. Ed., 2008, 47, 3122-3172); (c) D. McGuinness, Dalton Trans., 2009, 6915-6923.

10 E. Aldeco-Perez, A. J. Rosenthal, B. Donnadieu, P. Parameswaran, G. Frenking and G. Bertrand, Science, 2009, 326, 556-559.

11 The value given here is from ${ }^{1} \mathrm{H}^{29} \mathrm{Si}$ HSQC NMR. No resonances were observed in ${ }^{29} \mathrm{Si}$ NMR for 2 in $\mathrm{C}_{6} \mathrm{D}_{6}$.

12 G. Engelhardt, R. Radeglia, H. Jancke, E. Lippmaa and M. Mägi, Org. Magn. Reson., 1973, 5, 561-566.

13 K. C. Thimer, S. M. Ibrahim Al-Rafia, M. J. Ferguson, R. McDonald and E. Rivard, Chem. Commun., 2009, 7119-7121. 